DOSSIEE: "Vertentes da educação inclusiva".

\title{
Políticas públicas de Ação Afirmativa para indígenas na Universidade Estadual de Mato Grosso do Sul: a visão dos implementadores
}

\section{Affirmative action public policies for indigenous people at the State University of Mato Grosso do Sul: the perspective of the implementers}

Erika Kaneta Ferri (i)

Maria Helena Salgado Bagnato (ii)

(i) Universidade Estadual de Mato Grosso do Sul - UEMS, Campo Grande, MS, Brasil, erika@uems.br

(ii) Universidade Estadual de Campinas - UNICAMP, Campinas, SP, Brasil, mhbagnato@gmail.com

Resumo: Analisou-se a implementação de políticas públicas de Ação Afirmativa para indígenas na Universidade Estadual de Mato Grosso do Sul, com base em entrevistas com pró-reitores, comissão de acompanhamento dos cotistas e coordenadores de cursos. Constatou-se que, dos 856 indígenas ingressantes de 2004 a 2014, apenas 10,86\% se formaram, fato que pode estar associado a situações vivenciadas de preconceitos, dificuldades com a língua e barreiras culturais. Ao relatar casos de intolerância/resistência, além de parcas ações que abordam a diversidade e Ações Afirmativas, os implementadores reconhecem a formação como elitista. No entanto, afirmam que, embora pontuais, tais ações abrangem monitorias, atividades em grupo, disciplinas optativas, criação de um centro de estudos e implementação do projeto de extensão Rede de Saberes. Conclui-se que ainda são necessários avanços, bem como mecanismos que garantam a inclusão e um aparato que assegure condições mínimas de permanência.

Palavras-chave: ação afirmativa, povos indígenas, Educação Superior 
Abstract: To investigate the implementation of affirmative action public policies for indigenous students at the State University of Mato Grosso do Sul, Bravil, interviews were conducted with deans, members of the committee for quota-recipient support, and program coordinators. Of the 856 indigenous students admitted from 2004 to 2014, only 10.86\% graduated. This low rate might be associated with prejudice, poor mastery of formal Portuguese, or cultural barriers. The interviewees acknowledged the programs as elitist by reporting situations of intolerance/ resistance, and scant efforts to address diversity and affirmative action measures. The respondents recognized that, albeit isolated, these efforts existed in the form of tutoring, group activities, elective courses, the creation of a study center, and the implementation of the extended education project Rede de Saberes [Knowledge Network]. Further advances are still needed, as are mechanisms capable of ensuring inclusion and the minimum conditions for academic permanence.

Keywords: affirmative action, indigenous people, higher education

\section{Introdução}

Mato Grosso do Sul concentra aproximadamente 70 mil indígenas, em precárias condições de vida e com indicadores sociais alarmantes. Essa situação advém de longa trajetória histórica que tem como pano de fundo a luta fundiária, uma vez que o estado tem como principais fontes de desenvolvimento e renda a agricultura e a pecuária, do que têm decorrido inúmeras tensões entre indígenas e parte da sociedade envolvida (SESAI, 2012).

A Universidade Estadual de Mato Grosso do Sul (UEMS) e o estado de Mato Grosso do Sul são pioneiros na oferta de cotas para negros e índios, ao implementar políticas de Ação Afirmativa. Tal iniciativa atende a reivindicações de lideranças indígenas, de indigenistas e de professores indígenas, assim como de organizações não governamentais e instituições de ensino que atuam em prol da causa indígena.

A Educação Superior tem sido um dos caminhos procurados pelos indígenas para se apropriarem de outros conhecimentos e saberes e, dessa maneira, viabilizarem a ocupação de espaços na formulação de estratégias contra-hegemônicas (Lima, 2007). Os espaços escolares, assim como qualquer organização, são lócus de bases conflitivas, frutos de processos históricos que conformam o terreno político e organizativo em que se move cada comunidade escolar concreta (Apple, 2006; Molina, Lopes \& Achilles, 2011). 
Berman (1993) esclarece que, no processo de configuração de uma política em uma instituição de ensino superior (IES), há duas vertentes a considerar: a micro e a macroimplementação. O contexto da microimplementação é o da organização local e do prestador de serviços; o da macroimplementação corresponde ao processo pelo qual o governo federal executa a política em níveis locais.

Elmore (1996), analisando a implementação do modelo retrospectivo (backward mapping), aponta que os elaboradores de políticas não controlam a sua implementação e que a definição dessa não ocorre no topo da administração, mas sim no ponto em que as ações administrativas interceptam escolhas privadas. Assim, é no âmbito da implementação que se manifestam as concepções pessoais e profissionais dos funcionários a respeito do que deva ser a política pública.

Há três elementos do comportamento dos atores envolvidos que podem afetar sua capacidade e vontade de implementar uma política: o conhecimento (compreensão e discernimento); sua aceitação, neutralidade ou rejeição; e a intensidade de sua resposta (Van Meter \& Van Horn, 1996).

Cabe destacar que, quanto maior o número de envolvidos no processo de implementação, maior a probabilidade de que se manifestem dificuldades durante o processo. No entanto, a complexidade também pode ser um mecanismo de proteção e negação ao programa ou à política proposta.

Esses aspectos conduziram-nos à seguinte questão: Como está sendo implementada a política de Ações Afirmativas na UEMS, segundo o olhar de seus implementadores?

A partir dessa indagação, esta pesquisa buscou analisar a implementação, na UEMS, de políticas públicas de Ação Afirmativa, direcionadas aos povos indígenas no período de 2003 a 2014. O estudo teve por objetivos adicionais elucidar de que maneira as políticas de Ação Afirmativa foram implementadas pelos diversos segmentos dessa IES, identificar as dificuldades e as facilidades no processo de implementação das políticas de Ação Afirmativa e mapear as Ações/Atividades Afirmativas, as discussões sistemáticas e as ações programadas desenvolvidas na IES.

Os estudos sobre a implementação de políticas públicas são parcos, e a maioria centrase apenas em resultados, demonstrando hiatos entre o que é formulado e o que é 


\section{pro.posıções}

$e$-ISSN 1980-6248

http://dx.doi.org/10.1590/1980-6248-2016-0133

implementado, sendo os efeitos, por vezes, totalmente distintos dos objetivos e das metas almejados. Estudar a implementação a partir do olhar dos implementadores, no entanto, acrescenta uma nova dimensão à análise das políticas públicas, pois, ao proporcionar um ponto de vista, colabora-se com o debate e o intercâmbio, o que é particularmente relevante no caso da IES pesquisada, uma das primeiras a implantar um sistema de cotas e uma política de Ação Afirmativa.

\section{Metodologia}

Esta pesquisa qualitativa, descritiva e analítica constitui um estudo de caso conduzido em perspectiva político-organizacional. $\mathrm{O}$ estudo foi empreendido na sede administrativa da UEMS, em Dourados, e nas unidades universitárias de Aquidauana, Amambai, Campo Grande e Maracaju.

Houve 14 participantes $^{1}$ : 1 pró-reitor; 2 membros da comissão de acompanhamento dos alunos cotistas, que já ocuparam cargos de pró-reitores; e 11 coordenadores de cursos frequentados por 10 ou mais alunos indígenas. Tais cursos são listados na Tabela 1.

${ }^{1}$ Foram utilizadas as seguintes siglas para designar os participantes: PR (pró-reitor), OCPR (ocupou cargo de próreitor e foi membro da comissão de acompanhamento dos alunos cotistas), CC (cargo de coordenador) e OCC (ocupou cargo de coordenador). 
Tabela 1. Cursos com maior número de estudantes indígenas matriculados Universidade Estadual de Mato Grosso do Sul, 2013

\begin{tabular}{|l|c|}
\hline \multicolumn{1}{|c|}{ Curso e município que o sedia } & Alunos indígenas \\
\hline Direito (Dourados) & 17 \\
\hline $\begin{array}{l}\text { Letras, habilitação em português/espanhol e suas literaturas (Campo } \\
\text { Grande) }\end{array}$ & 14 \\
\hline Enfermagem (Dourados) & 11 \\
\hline Engenharia Florestal (Aquidauana) & 11 \\
\hline Geografia (Campo Grande) & 10 \\
\hline História (Amambai) & 16 \\
\hline Licenciatura em Letras (Dourados) & 23 \\
\hline Pedagogia (Campo Grande) & 10 \\
\hline Pedagogia (Maracaju) & 17 \\
\hline Pedagogia (Dourados) & 10 \\
\hline Zootecnia (Aquidauana) & 10 \\
\hline
\end{tabular}

Fonte: Dados da Pró-reitoria de Extensão e Assuntos Comunitários (UEMS, 2014)

O estudo, realizado pela primeira autora, foi autorizado pelo Comitê de Ética em Pesquisa da Universidade Federal de Mato Grosso do Sul (UFMS), Parecer 814.869/2014. Os participantes assinaram termo de consentimento livre esclarecido.

Para nos aproximarmos das percepções dos implementadores, aplicamos entrevistas, utilizando roteiro semiestruturado. As entrevistas, realizadas pela primeira autora, foram gravadas, armazenadas em equipamento eletrônico e transcritas na íntegra para posterior análise.

Os discursos colhidos foram analisados à luz da Educação Crítica e dos estudos de implementação de políticas públicas. O estudo compreendeu o período de 2003 a 2014, posterior à publicação da lei de cotas para negros e índios na IES investigada, e também período do governo no qual se ampliaram as políticas de Ação Afirmativa na Educação Superior no Brasil. 


\section{Resultados e discussão}

A apresentação dos resultados foi organizada a partir das percepções dos implementadores sobre a execução das políticas de Ação Afirmativa na instituição, permitindo identificar as seguintes categorias: a) presença indígena no campus; b) dualidade: visível e invisível - igual e diferente; c) fixidez; d) adversidades; e) intolerância e resistência; f) interstícios e entre-lugares; g) reconhecimento de uma formação elitista; h) programas e projetos de extensão de apoio estudantil.

\section{a) Presença indígena no campus}

Constatou-se aumento considerável na oferta de vagas no período de 2005 a 2013 (Tabela 2), decorrente da criação de novos cursos, entre eles o de História, em 2008, em Amambai; o de Engenharia Florestal em Aquidauana em 2006; e o de Geografia em Campo Grande em 2010. Esses são municípios com maior presença de povos e aldeias indígenas.

Tabela 2. Progressão na oferta de vagas, por ano de ingresso Universidade Estadual de Mato Grosso do Sul, 2005-2013

\begin{tabular}{|c|c|c|c|c|c|c|c|c|c|}
\hline Variáveis & $\mathbf{2 0 0 5}$ & $\mathbf{2 0 0 6}$ & $\mathbf{2 0 0 7}$ & $\mathbf{2 0 0 8}$ & $\mathbf{2 0 0 9}$ & $\mathbf{2 0 1 0}$ & $\mathbf{2 0 1 1}$ & $\mathbf{2 0 1 2}$ & $\mathbf{2 0 1 3}$ \\
\hline Vagas & 1.078 & 1.148 & 1.169 & 1.239 & 1.295 & 1.645 & 1.680 & 1.659 & 1.643 \\
\hline Negros & 308 & 328 & 334 & 354 & 370 & 480 & 480 & 474 & 470 \\
\hline Indígenas & 154 & 164 & 167 & 177 & 185 & 240 & 240 & 237 & 237 \\
\hline Total & 1.540 & 1.640 & 1.670 & 1.770 & $\mathbf{1 . 8 5 0}$ & $\mathbf{2 . 4 0 0}$ & $\mathbf{2 . 4 0 0}$ & $\mathbf{2 . 3 7 0}$ & $\mathbf{2 . 3 5 0}$ \\
\hline
\end{tabular}

Fonte: Dados do Relatório anual de atividades físico-financeiras, Universidade Estadual de Mato Grosso do Sul, janeiro/outubro de 2013 (UEMS, 2013)

A Tabela 3 revela que, no período de 2004 a 2014, dos 856 alunos indígenas ingressantes, 93 (10,86\%) concluíram a graduação, e, dos 3.071 alunos negros que ingressaram, $637(20,74 \%)$ concluíram essa formação. 
Tabela 3. Ingressantes e concluintes cotistas (negros e indígenas) Universidade Estadual de Mato Grosso do Sul, 2004-2014

\begin{tabular}{|c|c|c|c|}
\hline Cotistas & Ingressantes & Concluintes & Parcela de concluintes \\
\hline Negros & 3.071 & 637 & $20,74 \%$ \\
\hline Indígenas & 856 & 93 & $10,86 \%$ \\
\hline Total & 3.927 & 730 & $31.60 \%$ \\
\hline
\end{tabular}

Fonte: Dados do Plano de Desenvolvimento Institucional 2014-2018 (UEMS, 2014)

Em 2004, após a promulgação da lei de cotas para indígenas, 186 se inscreveram para o vestibular e 116 foram classificados. Apenas 67 efetuaram matrícula, a maioria (37) dos quais era do sexo masculino. Apenas 8 ingressantes terminaram a graduação em 2007. Um número tão baixo de concluintes revela serem necessários estudos mais profundos sobre a evasão estudantil, termo que designa um fenômeno educacional complexo, focalizado sob diferentes conceituações. Adotaremos aqui o termo "evasão" como sinônimo de fuga, desistência ou abandono de algo - no caso, abandono de um curso em algum ponto de seu decorrer (Cordeiro, \& Zarpelon, 2011).

Evasão e desistência são alguns dos tópicos discutidos por Veiga, citado por Veiga e D’Angelis (2010), ao apontar que a evasão escolar pode constituir uma forma de resistência à escola. No entanto, tal afirmação não pode ser generalizada, em vista da diversidade e da complexidade do fenômeno.

Um levantamento de 2009, empreendido pelo Centro Indígena de Estudos e Pesquisas (CINEP), já apontava a evasão, revelando que ao menos 20\% dos cerca de 6.000 estudantes indígenas de cursos de graduação em todo o País não conseguiam terminar seus estudos. A entidade aponta: "como fatores determinantes de evasão indígena nas universidades, o preconceito, a língua, a ausência de conteúdo básico das etapas iniciais da atividade escolar, além do baixo valor das bolsas" (Couto, 2009, p. 1).

No presente estudo, os entrevistados assim se referem à evasão e à desistência dos alunos indígenas:

a gente precisa investigar a questão da evasão .... Às vezes o pessoal tem um certo temor dos dados da evasão, porque você investe em um programa e uma das coisas que se esperava é que ele obtivesse sucesso com o maior número de alunos que permanecessem. (PR) 
não conseguimos formar muitos aqui. Entre as mulheres, tem a questão da gravidez̧ e elas amamentam por mais tempo que nós não indígenas. Dependendo se é uma mulher casada, ela vai dar prioridade à família e depois ela prioriza os estudos. (CC2)

boje vejo que o número de alunos nos cursos aqui diminuiu. Nós já tivemos muitos alunos e hoje já são menos ..., redurindo a procura pelos cursos aqui pelos alunos indígenas. (OCC2)

Focalizando os primeiros ingressantes na UEMS, em 2004, Cordeiro e Zarpelon (2011) analisaram a evasão de indígenas cotistas no período de 2004 a 2007, constatando que entre suas causas se destacavam as questões financeiras e o relacionamento professor-aluno.

Além disso, como se observa em uma das falas anteriormente mencionadas, para alguns grupos indígenas a família tem prioridade, por exemplo, no cuidado das crianças pequenas ou dos doentes.

Cordeiro (2008), em estudo sobre alunos cotistas da UEMS, percebeu que os indígenas se sentiam excluídos dos grupos por "falar diferente" (não dominar a língua portuguesa) dos não índios e ser considerados incapazes, além do fato de muitos professores discursarem contra as cotas em sala de aula.

Outro aspecto que chama atenção é a representação dos grupos étnicos entre os alunos indígenas. O relatório do Programa Rede de Saberes (2009) aponta a presença de 243 indivíduos Terena; 89, Kaiowá; 68, Guarani; 12, Kadwéu; 3, Xavante; 2, Kaingang; e 1, Kinikinau, além de 7 sem etnia informada. Comparandoesses números com os dados demográficos das etnias de Mato Grosso do Sul (Tabela 4), observa-se sub-representatividade de alguns grupos. De uma população Kaiowá de 34.500, apenas 89 alunos (0,25\%) estavam matriculados, enquanto em uma população Terena de 22.979, estavam matriculados 243 alunos (0,91\%); na população Kadwéu, de 1.350, os matriculados eram 12 (0,8\%). Já entre os 6 indivíduos da etnia Xavante no estado, 3 estavam matriculados (50\%). Essa subrepresentatividade perdura ainda na UEMS e pode estar relacionada à dificuldade de acesso e à baixa escolaridade, como revelam as pesquisas sobre alunos indígenas em Mato Grosso do Sul, de Bittar, Rodriguez e Almeida (2006) e de Brand e Calderoni (2012). 
Tabela 4. População indígena cadastrada no Sistema de Informação da Atenção à Saúde Indígena (SIASI), por etnia

Mato Grosso do Sul, 2012

\begin{tabular}{|c|c|}
\hline Etnia & População \\
\hline Kaiowá & 34.500 \\
\hline Terena & 22.979 \\
\hline Guarani & 11.043 \\
\hline Kadwéu & 1.350 \\
\hline Guato & 175 \\
\hline Kinikinau & 137 \\
\hline Ofaie & 60 \\
\hline Bororo & 53 \\
\hline Guarani Kaiowá & 48 \\
\hline Atokum & 30 \\
\hline Xavante & 6 \\
\hline Cinta Larga & 2 \\
\hline Total & 70.383 \\
\hline
\end{tabular}

Fonte: SESAI (2012)

\section{b) A dualidade: visível e invisível - igual e diferente}

O que se observa nos próximos relatos dos entrevistados é a dualidade entre visível e invisível, entre igual e diferente, no que se refere ao indígena e à sua presença no meio universitário:

No plano imediato, o projeto de cotas dentro da UEMS vem dar conta de um problema imediato, desnudar as pessoas, desnudar um problema que estava invisivel. (PR)

Esses programas e ações afirmativas conseguem trazer essas pessoas. Elas são os porta-vozes. (PR)

Os entrevistados revelam que as cotas possibilitam desnudar um problema, torná-los porta-vozes, porém não explicitam de que forma isso se daria, nem qual seria o papel dos diversos atores no cenário universitário.

Lima (2007) salienta que os alunos indígenas podem ser fenotipicamente muito parecidos com os habitantes regionais com que convivem, a ponto de serem até mesmo invisíveis como integrantes de coletividades etnicamente diferenciadas para seus professores e para a estrutura universitária de que participam. 
Quanto a isso, um entrevistado relata: "A forma como eles foram se formando, eles me parecem acostumados a serem invisiveis e também a ser tratados como invisiveis" (CC4).

Cabe ver este relato como fruto de uma longa trajetória histórica que colocou os indígenas nessa condição, obrigando-os a permanecer submersos por meio do silenciamento ou do esquecimento, mediante diversas formas de supressão de seus direitos fundamentais (Santos, 2010).

No entanto, um dos participantes ressalva que: "Professores mais sensiveis acolhem, e outros professores tratam de maneira normal, como outro aluno qualquer" (OCPR/CC).

Bourdieu (1997) afirma que, ao tratar todos da mesma forma - inclusive o "diferente" -, a escola privilegia dissimuladamente quem já é privilegiado por sua bagagem familiar.

Nessa ótica, a inércia ou o tratamento de todos como iguais podem carregar representações previamente construídas, estereótipos e prejulgamentos de uma sociedade impregnada pela imagem do índio de forma generalizada.

A normalização é um processo sutil no qual o poder se manifesta no campo da identidade e na diferença. Normalizar significa eleger uma identidade para parâmetro em relação às demais e, dessa forma, servir a avaliações e hierarquizações (Silva \& Real, 2011).

Os alunos, e em especial os indígenas, trazem em sua diversidade ${ }^{2}$ um reflexo de seu desenvolvimento cognitivo, afetivo e social, na maioria das vezes marcado por experiências e relações sociais já excludentes ao longo de suas trajetórias de vida. Um tratamento uniforme só consagra as desigualdades e as injustiças das origens desses grupos historicamente excluídos. Dayrell (1996) afirma:

Uma outra forma de compreender esses jovens que chegam à escola é apreendê-los como sujeitos socioculturais. Essa outra perspectiva implica superar a visão homogeneizante e estereotipada da noção de aluno, dando-lhe um outro significado. Trata-se de compreendê-lo na sua diferença, enquanto indivíduo que possui uma historicidade, com visões de mundo, escalas de valores, sentimentos, emoções, desejos, projetos, com lógicas de comportamentos e hábitos que lhe são próprios. (p. 5)

\footnotetext{
2 O conceito de diversidade é aqui compreendido como construção histórica, cultural e social das diferenças. Tais diferenças podem ser de gênero, raça, religião, etnia, cultura, política, condição social, estado físico e orientação sexual, entre outros. Segundo Woodward (2009), diversidade e identidade se constroem em determinado contexto social, histórico e político.
} 
Compreendê-los a partir de suas diferenças constitui abordagem que permite acolher o diverso, em um processo em que a troca de saberes é promovida na prática pela diversidade ${ }^{4}$. Neste enfoque, não se pode priorizar o reconhecimento somente da igualdade; há que se buscar movimentos que discutam as diferenças. No entanto, como qualquer luta concebida sob a égide de um desses princípios, deve ser organizada de maneira a abrir espaço ao outro (Santos, 2009).

Mais um aspecto a destacar é a marcação da diferença, compreendida também como mecanismo para marginalizar, estereotipar e excluir grupos e indivíduos. A diferença pode ser construída negativamente por meio da exclusão ou da marginalização daqueles que são definidos como "outros", ou forasteiros (Woodward, 2009). Neste aspecto, considera-se que manter um diálogo baseado no respeito às diferenças é complexo, exige movimentos e mecanismos como formas de conhecimento/reconhecimento desse outro.

Discutir a diferença exige abordar a identidade. Woodward (2009) afirma que a identidade depende da diferença, mas não o oposto. Nas relações sociais, diferenças simbólicas e sociais são estabelecidas, ao menos em parte, por meio de sistemas classificatórios.

Em sociedades de supremacia branca, por exemplo, ser branco não é considerado uma identidade étnica e racial. A força homogeneizadora da identidade é diretamente proporcional à sua invisibilidade (Silva, Hall, \& Woodward, 2011).

Desse modo, políticas de Ação Afirmativa atendem ao direito constitucional à diferença. Tal direito, no entanto, é ainda questionado: "Devemos tratar todo mundo igual. Procurar fazer que a lei seja para todos. Por que os indios devem ser tratados diferentes? Por que o indio deve ter cota? " (CC5).

Como se observa nessa fala, o discurso ideológico de igualdade denota uma tentativa de diluir a noção de diferença, em uma lógica de pluralismo conservador e integrador.

Nesse sentido, Silva e Souza (2008) apontam que "ver a identidade e a diferença como uma questão de produção significa tratar as relações entre as diferentes culturas não como uma questão de consenso, de diálogo, ou comunicação, mas como uma questão que envolve fundamentalmente relações de poder" (p. 96). 


\section{pro.posıções}

http://dx.doi.org/10.1590/1980-6248-2016-0133

\section{$e$-ISSN 1980-6248}

\section{c) Fixidez ${ }^{3}$}

A educação tem papel fundamental na ressignificação de identidades marginalizadas por processos que levam à inferiorização e à exclusão. Apesar de esforços recentes, parte das escolas não contempla, em suas práticas pedagógicas, questões relacionadas à pluralidade cultural.

Tal fato pode ser entendido, considerando que a Educação Superior, por diversas vezes, tem sido um "veículo de projeção, de padrões e modelos que impedem o verdadeiro conhecimento, privilegiando um conhecimento dado e assimilado" (Gusmão, 2003, p. 92), tipicamente representando o colonizado como degenerado (Bhabha, 2007).

Nessa direção, Giroux (1997) aponta

o que vale como conhecimento, o que é importante ensinar, a forma como se julga o objetivo e a natureza do ensino, da forma como se vê o papel da escola na sociedade e a compreensão dos interesses sociais e culturais que modelam todos os níveis da vida escolar. (p. 16)

Entre os entrevistados, se observa-se exígua discussão sistemática sobre o tema:

No curso não há discussões sistemáticas para discutirmos isso. Nunca bouve uma discussão do que fazer, por exemplo. (OCC1)

Os projetos políticos pedagógicos (PPP) mantêm uma lógica da formação profissional. Não têm o cuidado, a situação do negro e do indio no Brasil. O PPP não contempla absolutamente nada de Ações Afirmativas. (OCPR/CC)

Tais relatos revelam que a presença indígena nessa IES não conduziu a discussões sobre a situação dos índios e dos negros no Brasil. O desafio é a construção de um currículo que leve em conta as características etnorraciais e culturais dessas populações, rompendo com o modelo hegemônico e repetitivo de uma população urbana, branca e de classe média. Cabe entender a diversidade como riqueza e não como problema. "É imprescindível uma política educacional que reconheça que é no conjunto das diferenças que encontramos nossa própria identidade de brasileiros" (Silva \& Souza, 2008, p. 185).

\footnotetext{
${ }^{3} \mathrm{Na}$ fixidez, compreende-se algo como se estivesse sempre no mesmo lugar (fixo) (Bhabha, 2007).
} 


\section{pro.posıções \\ e-ISSN 1980-6248}

\section{d) Adversidades}

São recorrentes nas falas as dificuldades vivenciadas pelos estudantes indígenas. Os entrevistados ressaltam como origem dessas dificuldades a qualidade do Ensino Fundamental e Médio:

Se as pessoas tivessem as mesmas condições para se entrar na universidade, então eles não precisariam das cotas. A atuação do governo deveria ser na base, na qualidade do ensino público. (OCPR/CC)

os alunos indigenas têm muitas dificuldades. Eles chegam à universidade com um nivel de escolaridade muito baixo. (OCC1)

Alguns professores fazem correlação com as cotas, dizendo que eles são fracos, que não conseguem acompanhar, são preguiçosos. (OCC2)

Enfatizando que a política de Ação Afirmativa é necessária, Moehlecke (2002) também afirma ser necessário olhar a raiz do problema, que, no caso, inclui a baixa qualidade do ensino básico na esfera pública e deficiências em saúde, moradia, saneamento básico, segurança, emprego e renda, entre outros aspectos.

As cotas e as políticas de Ação Afirmativa não excluem a necessidade de discussões sobre o compromisso de melhorar a educação em todos os níveis. Devem também ser combinadas com outras políticas, para, de fato, combater a exclusão social vigente no País.

É preciso encarar os desafios a serem superados na educação básica nas comunidades indígenas, os quais podem estar relacionados a fatores como aulas em locais improvisados (galpões, casas de reza), carência de professores com nível superior (apenas 13\% dos professores de escolas indígenas cursaram graduação) e falta de pertinência cultural, além de fatores socioeconômicos (Aylwin, 2009).

Também é necessário considerar que o conhecimento dos alunos indígenas é construído sobre arcabouços culturais distintos. O desafio, portanto, está em como pensar uma aprendizagem significativa a partir de significados tão distintos.

Oliveira Filho, citado por Urquiza, Nascimento e Espíndola (2011) diz que "o problema das populações indígenas não é a baixa escolaridade, mas sim o reconhecimento e promoção de valores e visões de mundo diferenciados e ao empoderamento das sociedades" (p. 87). 


\section{pro.posıções}

$e$-ISSN 1980-6248

\section{e) Intolerância, preconceito e resistências}

No relato de uma das entrevistadas, emerge a questão do preconceito. O trecho praticamente completo está aqui transcrito, por se tratar não tão somente de uma situação explícita de preconceito e racismo, mas também de uma desqualificação do saber do outro:

vivi um preconceito na escola onde tinha o estágio em relação a uma aluna indígena. Era uma implicância exagerada, porque eu tinha outras estagiárias. No caso da aluna indígena, a professora sempre colocava, sempre ampliava alguma "falta", algum esquecimento.

A coordenadora me disse: "Tivemos uma professora que se queixou muito da sua estagiária". Na realidade, se não fez do jeito que a professora fez, é porque a aluna é indígena.

O trabalho que esta aluna fer. foi um trabalho inédito. Esta aluna é Terena e nós trabalhamos as lendas terenas. As crianças aprenderam cinco lendas inéditas e aprenderam também os nomes dos animais na lingua terena. Ela qualificou aquele projeto de modo diferenciado.

Eu sinto uma resistência das escolas em receber o estagiário indígena. Um olhar diferente: será que ele vai dar conta? Esta professora chegou a insinuar isto para mim, me dizendo assim: "Esta aluna vai dar conta? Será que ela vai dar aula aqui ou na comunidade dela? ". (CC2)

Mas o que vejo é a questão do preconceito. Da resistência e do preconceito. (CC1)

Nas situações de preconceito vivenciadas, a marcação da exclusão pode ser dada pela via do modelo hegemônico branco e rico: o pobre discriminado por ser pobre; o índio por ser índio; o negro, por ser negro. O mesmo se aplica a outros grupos minoritários.

Nos relatos colhidos por Athayde (2010), os entrevistados foram enfáticos ao descrever situações de preconceito vivenciado no âmbito universitário.

Há nitidamente uma desqualificação do saber indígena. Nas palavras de Antonio J. Brand, citado por Lázaro (2013), “os cursos não estão abertos para dialogarem com saberes locais ou tampouco incluírem essas questões nos currículos” (p. 15).

A inclusão de novos saberes nos espaços universitários tem sido um campo ainda pouco valorizado e explorado pelos professores. Como possibilidade de integrar um conjunto de novos saberes à comunidade acadêmica não indígena, podem-se destacar suas práticas indígenas de manejo ambiental, de cuidado à saúde e de agricultura, entre outras (Athayde, 2010). 
Há que considerar também os saberes dos jovens indígenas que, mesmo não vivendo em territórios tradicionais, trazem consigo seus saberes prévios e suas histórias de vida, que devem ser respeitados.

No presente estudo, os entrevistados também enfatizam situações de resistência nas atitudes, expressas nas falas dos colegas professores e também de alunos:

Temos professores que têm resistência ao acadêmico indigena, e toda vez que você toca nesta questão ele diæ: "Eu não oriento TCC, não oriento iniciação científica e eu não sou obrigado". (CC2)

Nesta semana mesmo recebi duas alunas para falar de uma aluna indígena que está se sentindo excluida dentro da sala de aula. (CC2)

Tais relatos apontam situações de preconceito e discriminação que podem advir de crenças, visões distorcidas e estereótipos construídos no contexto de uma sociedade envolvente que é preconceituosa e racista.

Silva et al. (2011) sugerem que uma estratégia pedagógica para tais situações seria a de tratar essas atitudes como desvios de conduta e proporcionar atividades, dinâmicas de grupo, exercícios corporais e dramatizações capazes de promover processos de conscientização que levem a mudanças de atitude entre estudantes e professores, bem como entre os demais servidores da instituição. Os autores reiteram que, ao tratar o tema da diversidade por meio do currículo e ações pedagógicas, as instituições de ensino o discutem como categorias de exotismo e objetos de curiosidade.

Assim sendo, Silva e Souza (2008) centram-se na defesa de uma pedagogia e um currículo baseados na identidade e na diferença como uma questão política, na discussão aprofundada de como a diferença é produzida, no entendimento de que as relações sociais entre índios e não índios no Brasil vêm ocorrendo historicamente em contextos assimétricos de distribuição de poder.

Portanto, propor discussões sobre diferenças culturais é reconhecê-las e também assumir que o País traz um ranço da retórica desenvolvimentista. Reconhecer a discriminação é sempre confuso, difícil e sutil (Lima, 2007). 
Nesse âmbito, as IES podem, em seu trabalho cotidiano, influir decisivamente na consciência da sociedade brasileira, de modo a questioná-la, subvertendo seus valores etnocêntricos.

\section{f) Os interstícios e os entre-lugares ${ }^{4}$}

Para se empreenderem mudanças, Lynch, Crean e Moran (2013), baseando-se em Habermas, apontam ser necessário identificar e compreender os interstícios (lugares entre os espaços que permitem que mudanças e resistências ocorram em momentos diferentes).

Diante das dificuldades relatadas pelos entrevistados, alguns cursos buscam saídas, ofertando projetos de ensino ou monitorias. No entanto, essas ações e esses projetos não são contínuos e, na maioria dos casos, não contam com recursos financeiros.

tem um projeto, que está com o apoio de um professor ... que presta atendimento aos alunos do primeiro ano, não especificamente com cotista. Principalmente para a leitura e interpretação de texto. (CC2)

Não existem açoes sistemáticas. Fica a cargo de cada professor, como é hoje, no sentido de trabalhar com monitorias e com projetos de ensino. (OCPR/CC)

Decidi fazer aulas práticas só pra indígenas. E foi muito bom. Eles conversavam e tiravam dúvidas. $A$ discussão se iniciou como os alunos trabalhavam os nomes das plantas na lingua. (OCC2)

Os avanços não são rápidos, com já apontado por Brostolin e Cruz (2010), mas podem ser percebidos, tanto nas entrevistas quanto nas tentativas dos cursos de buscar alternativas e novas possibilidades. Um exemplo disso, na presente pesquisa, foi o curso de Enfermagem, que, ao reestruturar seu Projeto Político-Pedagógico, propôs incluir a disciplina optativa Antropologia da Saúde, promovendo um debate sobre diversidade, cultura e etnocuidado ${ }^{5}$.

\footnotetext{
${ }^{4}$ Utilizaremos o conceito de entre-lugar. proposto por Bhabha (2007): o marginal e o estranho, o entre-lugar deslizante, a desestabilização dos essencialismos; convoca, enfim, o espaço-cisão da enunciação, um elo como espaço indeterminado dos sujeitos da enunciação.

5 Madeleine Leininger cunhou os termos "enfermagem transcultural" e "etnocuidado", ao focalizar diferentes culturas quanto ao cuidado cultural e fenômenos da saúde e da enfermagem (Leininger, 1991, citado por Rohrbach-Viadas, 1998).
} 
Entre os entrevistados há preocupação em conhecer e aprofundar-se na temática indígena:

Atualmente estou fazendo um curso de educação intercultural indígena, mas são coisas que en fui atrás. Por que en fui atrás? Embora a gente tenha no curso que aborde a questão indígena, que trazem estas discussões sobre a escola indigena. (CC2)

Buscando o debate sobre a inclusão na perspectiva de raça, etnia e gênero, foi criado o Centro de Estudos, Pesquisa e Extensão em Educação, Gênero, Raça e Etnia (CEPEGRE), visando subsidiar, articular, propor, monitorar e avaliar as políticas públicas de Ação Afirmativa na UEMS ligadas a educação, gênero, sexualidade, raça e etnia, com foco no processo de inclusão para acesso, permanência e conclusão na educação superior.

Assim, iniciativas, caminhos e propostas, mesmo que incipientes, são observados na busca por respostas às demandas e às necessidades de cada curso.

\section{g) Reconhecimento de uma formação elitista}

A Educação Superior tem sido marcada por uma dualidade: de um lado, tem mobilizado a luta por uma educação de qualidade para todos; de outro, ainda conserva ranços de uma formação conservadora e elitista.

Mesmo que o objetivo da presente pesquisa não seja comparar, agrupar e classificar os relatos dos entrevistados, constatam-se nítidas posições ideológicas, frutos da formação universitária.

Paz (2013) aponta que algumas instituições educativas se organizam sob uma lógica capitalista e um discurso neoliberal, em que o conhecimento válido é o produzido pela ciência hegemônica.

Santos (2009) salienta

que as estruturas (nelas aqui incluímos a Universidade) não são incompatíveis com uma concepção retórica do conhecimento ..., sem serem necessariamente, as estruturas locais de produção de lugares comuns e de senso comum. Uma vez construídas retoricamente, as estruturas tanto podem constituir premissas à argumentação, zonas de forte consenso sobre possibilidades de ação, como argumentos sobre a solidez e a resistência na prática social. (p. 263) 
Para Luciano (2006), indígena e pesquisador na área de educação dos povos indígenas, essa resistência já era esperada, se for considerado o secular sistema educacional brasileiro, profundamente excludente, discriminador e colonizador: "A cultura política e acadêmica sempre foi o baluarte do processo dominador e colonizador das sociedades ocidentais europeias, razão pela qual sempre mantiveram as portas das universidades cerradas para os povos colonizados" (p. 163).

Os entrevistados reconhecem que as IES são carregadas de marcas de uma formação para a elite: A universidade não entendeu que tinha gente lá fora se mobilizando. Não se deram conta. É muito difícil. De
que grupo você vem? (OCPR2)

Muitos professores vieram de grupos historicamente excluidos. Mas ascendem e omitem, não fazem mais parte desse grupo. Quando este grupo chega à universidade e se depara com estes grupos até se chocam. (OCPR2)

Eu lembro que quando levantaram as cotas, uma das preocupacōes que eu tinha era o discurso de onde estava impregnado do lugar da onde eu vinha, ou seja, o que era importante era investir na educação básica de todos, independente do recorte social, assim de renda, de cor. Aliás, o importante era que todos tivessem uma escola de qualidade na base. (PR)

A universidade é uma instituição social, ou seja, seu papel vai além das necessidades técnicas, científicas e de formação de recursos humanos para o mercado de trabalho. Inclui essencialmente o compromisso com os direitos humanos, entrelaçado com questões de qualidade de vida, qualidade ambiental, democracia, respeito, inclusão e solidariedade, em um contexto globalizado e de paz mundial.

Neste sentido, Santos (2010) afirma que

a universidade está sendo duplamente desafiada pela sociedade e pelo estado, e não parece estar preparada para se defrontar com os desafios, muito menos com as transformações profundas necessárias e também não para simples reformas parcelares. Este cenário, em parte, é originário da rigidez funcional organizacional e estrutural das IESs públicas do Brasil. (p. 56)

Portanto, como instituição social, a universidade é um lugar composto por uma estrutura do espaço social em que se situam as frias estruturas do espaço físico. Segundo Bourdieu (1997): 
Os agentes sociais que são constituídos como tais em e pela relação com um espaço social (ou melhor, com campos) e também as coisas na medida em que são apropriadas pelos agentes, portanto, constituídas como propriedades, estão situadas num lugar do espaço social que se pode caracterizar por sua posição relativa pela relação com os outros lugares (acima, abaixo, entre, etc.) e pela distância que os separa deles ... também pode ser definido pela exclusão mútua, isto é, como uma justaposição de posições sociais. (p. 167)

A estrutura do espaço manifesta hierarquias e distâncias sociais, e o poder sobre o espaço tem, de certa forma, relação com a posição social. As universidades públicas continuam sendo um espaço ocupado pelas elites e pela burguesia.

\section{h) Programas e projetos de extensão de apoio estudantil}

$\mathrm{Na}$ instituição pesquisada, os programas de apoio estudantil específicos para indígenas são o Programa Vale Universidade Indígena (PVUI) e o projeto de extensão Rede de Saberes. Este último, criado em 2005, visa desenvolver ações de apoio aos alunos indígenas em sua trajetória acadêmica, em conjunto com a Universidade Católica Dom Bosco (UCDB).

Segundo o relatório do Programa Rede de Saberes (2009), as principais ações desenvolvidas são "O apoio à participação dos acadêmicos em atividades de pesquisa, capacitação de docentes, estudantes e pessoal administrativo das IES, apoio à participação e/ou organização de eventos acadêmicos voltados para a temática indígena” (p. 7).

Segundo uma das entrevistadas, o objetivo do programa é "apoiar. Monitoria e tutoria devem ser institucionalizadas por pessoas que estejam sensibilizadas pela causa. Nossos tutores são sensibilizados para as questões indígenas, são professores da rede" (OCPR2).

Urquiza et al. (2011, p. 12) entendem que as atividades desenvolvidas pela UEMS por meio do programa Rede de Saberes "têm ajudado a articular relações interétnicas, baseadas no respeito à diversidade cultural e no dinâmico processo de se tomar consciência sobre a necessidade de se estabelecer maior equidade e justiça em uma sociedade multiétnica como a nossa".

O projeto também promove a visibilidade e o acolhimento do aluno indígena: "Pois, diziam: 'A gente fica pelos cantos, a gente se reúne e fica pelos cantos. A gente não tem um lugar'. Uma vez. eu vi escrito na parede do Rede: 'A oca dos indios" (OCPR2). 
O projeto enfrenta dificuldades. Mesmo com amplo apoio da IES, há problemas em sua manutenção e também na oferta a todas as unidades universitárias que contam com alunos indígenas. Trata-se de um projeto de extensão e não um programa institucional, ou seja, é dependente de financiamento externo. Berman (1993) fala que a prestação de serviços locais sistematizados e institucionalizados tem maior chance de produzir resultados positivos.

Nesse sentido, um dos entrevistados informa que "o Rede de Saberes funcionou bem aqui, mas agora nem sei. Tinha aulas extras. Hoje, que eu saiba, não tem nada do Rede funcionando. Funcionava bem melhor. Acho que boje está tudo parado" (OCC2).

Observou-se entre os entrevistados um contraste entre os que conhecem e os que alegam conhecer parcialmente os programas, as ações para o apoio estudantil e o projeto Rede de Saberes. "Fica difícil dizer que o coordenador esteja amparado para orientar o acadêmico indígena em todas as possibilidades e ofertas que a instituição tra\%.... Às vezes os professores não conhecem os programas" (CC1).

O PVUI, por sua vez, favorece estudantes indígenas de baixa renda (UEMS, 2014). Oferece 120 bolsas, mas em 2014 beneficiou apenas 54 alunos. Segundo uma das entrevistadas: "As pessoas podem olhar as bolsas e ver só os números e dizer que os índios não querem. Não é que eles não querem; o programa é excludente de inicio" (PR).

O PVUI hoje enfrenta muitas críticas, pois, no entendimento da comunidade acadêmica, não supre as necessidades de manutenção do aluno na universidade, situação agravada por seu caráter excludente e meritocrático: o aluno pode ser excluído do programa, se, no decorrer da graduação, acumular mais de três disciplinas em regime de dependência ou tiver de cumprir carga horária em locais que não atendam à sua formação acadêmica.

Os entrevistados expuseram posições contrárias aos critérios estabelecidos para a obtenção da bolsa aos montantes mensais repassados aos alunos:

Os alunos dizem: "Olha, professora: nós não vamos ficar com essa bolsa, 'eles' vão lá pra ver se tu está lá, e se você não está lá eles nem perguntam por quê. É uma burocracia. A gente ganha mais faẓendo qualquer outra coisa, por exemplo: como ajudante de pedreiro". (OCPR2)

não encaixava nos nossos cursos: nosso curso tem 28 horas e a semana tem 40. Como é que os alunos vão cumprir 20 horas? Então precisamos adequar horários. Ajustar, ajustar os sábados. (OCC2) 
Quanto à efetividade do programa, os entrevistados declaram:

os programas que a nossa universidade tem nesse momento, agora eles ainda estão muito aquém a dar acesso ao sujeito para alcançar esse mérito. Então hoje, a gente, muitos alunos perdendo bolsa no Vale Universidade Indigena do estado. Por quê? Porque tem três reprovacõees e ele é convidado a se retirar. (PR)

o programa é excludente. (OCPR2)

Os alunos utilizam a bolsa para custear despesas pessoais:

ele pegava uma bolsa e tinha que sair quatro ou cinco horas da manhã passar o dia todo, não comer, ficar suado, chegar meia-noite na casa dele pegar uma bicicleta. É óbvio que esse menino não vai sobreviver por muito tempo, aí, até que um dia esse menino some e ele foi trabalhar com o tio dele de auxiliar de pedreiro, porque ele trabalhar na cidade ele estará próximo da comunidade da sua casa. Aquilo faz sentido para a vida dele.

E a universidade? Não conseguiu dar conta. Porque o programa da política, ela não pode ser de uma maneira generalista, que olha as pessoas, e é difícil fazer isso, mas ela não pode olbar a massa, o amorfo. (PR)

Van Meter e Van Horn (1996) indicam que as políticas dependem de outros elementos, além de normas e objetivos, para que sua implementação se viabilize. Para administrá-las é igualmente necessária a provisão de recursos - que podem ser financeiros ou outros incentivos para estimular ou facilitar a implementação efetiva.

A dependência governamental e os programas de apoio que não atendam às demandas e às especificidades dos grupos eleitos como foco das ações propostas podem representar um grave obstáculo à implementação de uma política. No programa de bolsas específico para alunos indígenas, o que se observa é um descompasso no propósito do governo estadual, com obstáculos de toda ordem à permanência desses alunos nos programas de apoio.

Nesse mesmo pensamento, Lima (2007) afirma que:

No caso da ... UEMS ... alunos indígenas cotistas ... ficam obrigados a trabalhar em atividades administrativas, funcionando como mão de obra remunerada por "bolsas de trabalho" [ênfase no original], tendo parte de seu tempo roubado da possibilidade de superar dificuldades de adaptação. (p. 25).

O programa se torna excludente, ao adotar critérios como a impossibilidade de acúmulo de uma ou mais bolsas; a não concessão, simultânea, do benefício a irmãos; a 
incompatibilidade de carga horária em cursos de graduação em horário integral; e excesso de burocracia.

A carga horária pode ser cumprida em locais designados pela Pró-Reitoria de Extensão ou o aluno pode vincular-se a alguma atividade de extensão ou pesquisa com professores da instituição. Situações desconfortáveis podem ser percebidas quando os alunos são acolhidos por professores em seus projetos de extensão e de pesquisa: "Tem uma desconfiança muito grande do man uso do recurso público, que indio protege indio, on que professor da universidade protege os indios" (OCPR2).

Os aspectos expostos levam a um questionamento: quais são os movimentos políticos verdadeiros que o governo estadual de Mato Grosso do Sul promove em defesa dos povos indígenas? Levantando hipóteses de que o cenário político estadual seja desfavorável a discussões e proposições voltadas às questões indígenas, a bancada ruralista e outras pressões tendem a manter em inércia boa parte de seus representantes legislativos.

É necessário repensar os programas de apoio estudantil e adaptá-los aos novos sujeitos que ingressam na universidade, considerando suas particularidades, uma vez que o apoio político externo à política de Ação Afirmativa adotada pela IES fica centrado em discursos e propostas, sem ações efetivas que se concretizem. Quando essas se materializam, não promovem as discussões necessárias para garantir a permanência dos alunos indígenas na universidade.

\section{Considerações finais}

Sem pretender exaurir a discussão sobre a temática, as universidades, como toda organização, são lócus de bases conflitivas e complexas, resultantes de processos históricos que conformam o terreno político e organizativo, compondo-se de sujeitos singulares, oriundos de um contexto intrincado e frutos de construção histórica e social.

Nesse cenário complicado, e muitas vezes adverso, é que se propõe configurar a política de Ação Afirmativa para indígenas na UEMS, hoje imbricada em um contexto político local marcado por um ranço histórico de negação aos direitos fundamentais da população indígena sul-mato-grossense. 
A partir da proposta de análise da implementação da política de Ações Afirmativas nessa instituição, segundo o olhar de seus implementadores, buscou-se delinear uma nova dimensão para a análise das políticas públicas, pois na sua concretização se manifestam as concepções pessoais e profissionais dos funcionários envolvidos, considerando que a função central da análise da implementação consiste em identificar os fatores que condicionam a efetivação dos objetivos normativos ao longo de todo o processo.

Do ponto de vista percepção dos implementadores, no que se refere à presença indígena no campus, constatou-se a preocupação dos entrevistados com a evasão e a desistência dos estudantes indígenas, bem como sua sub-representatividade, especialmente dos maiores grupos populacionais do estado - fenômenos esses que necessitam de maiores investigações.

Observou-se dualidade nos relatos dos entrevistados sobre a presença desses alunos no campus: por um lado, julgam essa presença importante, pois dá visibilidade aos problemas que os povos indígenas enfrentam, mas ao mesmo tempo consideram que a comunidade acadêmica tende a mantê-los invisíveis. Pressupondo que devem ser tratados como "iguais", relatam que alguns colegas professores os tratam como qualquer outro aluno, ao passo que professores "mais sensíveis" os acolhem.

Os participantes destacam as dificuldades vivenciadas pelos universitários indígenas, e consideram que sua origem reside na baixa qualidade do Ensino Fundamental e Médio, o que se soma às diferenças culturais.

Os entrevistados enfatizam que as cotas possibilitam desnudar um problema, torná-los porta-vozes, porém não explicitam de que forma isso se daria, nem qual seria o papel dos diversos atores no cenário universitário.

Os relatos revelam que a presença indígena nessa instituição não conduziu a discussões sobre a situação dos índios e dos negros no Brasil, pois no curso não há discussões sistemáticas sobre a temática e os projetos políticos pedagógicos mantêm a lógica da formação técnica profissional.

Narram também situações de intolerância, preconceito e resistência, vivenciadas a partir da presença indígena no campus, e a postura e a atitude pessoal dos indígenas diante de tais situações. Pontuam ainda a busca por saídas, com ações e atividades, mesmo que pontuais, e alternativas, como monitorias, atividades em grupo, disciplinas obrigatórias e optativas que 
contemplem a temática indígena, criação do CEPEGRE e atividades de apoio desenvolvidas no âmbito do projeto de extensão Rede de Saberes.

Evidenciou-se que a bolsa de permanência do governo estadual (PVUI) não supre e não respeita as necessidades e as especificidades dos alunos indígenas, além de ter caráter excludente. São também insuficientes os incentivos financeiros recebidos pela UEMS para a implementação efetiva de uma política pública eficiente nesse contexto. A ausência de uma estrutura consolidada para que a instituição possa desenvolver ações afirmativas consistentes não assegura a inclusão.

Observaram-se nos relatos dos implementadores entrevistados três comportamentos distintos quanto à avaliação da política de Ação Afirmativa: conhecimento, compreensão e discernimento sobre as questões indígenas, relatadas como incipientes; neutralidade ou rejeição; e mecanismos de busca para a inclusão e o acolhimento efetivo do estudante indígena somente por alguns profissionais.

Os implementadores reconhecem uma formação elitista. Destacando "o lugar de onde veio", apontam que muitos professores provieram de grupos historicamente excluídos, "mas ascendem e se omitem". Portanto, hodiernamente esses sujeitos podem estar vivenciando altercações pessoais, pois muitas universidades brasileiras foram e ainda são pautadas por uma lógica capitalista e um discurso neoliberal.

Romper com a postura de inércia e silenciamento exige discussões aprofundadas e ações efetivas para combate ao preconceito contra indígenas e às visões distorcidas sobre eles. Além disso, as políticas redistributivas trazem em seu cerne elementos descritos por alguns como "polêmicos", como é o caso da política de Ação Afirmativa.

A cada momento da história, as instituições, as forças e os processos estruturados interferem nas relações e nas ações dos sujeitos, mas, simultaneamente, são produzidos, instituídos e estruturados pela práxis desses mesmos sujeitos. Dessa forma, os sujeitos são, ao mesmo tempo, produtos e produtores de relações e instituições que eles mesmos engendram e pelas quais são engendrados.

Constata-se que a presença de alunos indígenas na UEMS se configura como significativa, visto que parte da população desconhece por completo a temática e os determinantes envolvidos em todas as questões indígenas. 
Há de se pensar em estratégias que garantam os princípios constitucionais de igualdade e respeito às diferenças de forma articulada, dado que o respeito à diferença perpassa as garantias dos direitos humanos, como políticas de assistência, habitação e trabalho, saúde, moradia e acesso a bens e serviços, além do direito à terra, entre outras necessidades essenciais.

As populações indígenas, especialmente as localizadas no sul do estado, encontram-se hoje em um cenário de luta para obter garantias mínimas de sobrevivência, situação que revela a violação completa de seus direitos. Nesse aspecto, pode-se afirmar que a política de Ação Afirmativa deve ser mais ampla, sem restringir-se às minorias raciais no enfoque educacional: deve ser estendida à extinção das mazelas de ordem socioeconômica que afetam o País. Portanto, muito ainda há a fazer para que se conte com uma ação política emancipatória.

A política da UEMS é inédita e, como tal, enfrenta forças opositoras, tornando mais premente criar caminhos e novas formas de superá-las. Nesse âmbito, é necessário considerar não apenas suas urgentes demandas materiais, mas, também, e especialmente, sua visão de mundo, sua cosmologia e os desafios subjetivos que os alunos indígenas experimentam quando adentram instituições universitárias.

Dessa forma, com base no marco teórico de análise de implementação de políticas públicas, a partir da visão dos implementadores, verifica-se que a instituição aqui focalizada ainda precisa avançar na combinação de recursos humanos e materiais, bem como no estímulo ao envolvimento e à motivação dos implementadores, para o efetivo sucesso de políticas emancipadoras. 


\section{pro.posıções \\ $e$-ISSN 1980-6248}

\section{Referências}

Apple, M. W. (2006). Ideologia e curriculo (3a ed., V. Figueira, trad.). Porto Alegre: Artmed.

Athayde, F. L. O. (2010). Ações Afirmativas, cotas e a inserção de acadêmicos indígenas na Universidade Estadual de Mato Grosso do Sul (UEMS). Dissertação de Mestrado, Universidade Católica Dom Bosco, Campo Grande, MS, Brasil.

Aylwin, J. (2009). Os direitos dos povos indígenas em Mato Grosso do Sul, Brasil: confinamento e tutela no século XXI (Informe 3, International Work Group for Indigenous Affairs). São Paulo: IWGIA.

Berman, P. (1993). El estúdio de la macro e micro implementación. In L. F. Aguilar Villanueva, Antologías de la política pública (pp. 281-321). México: Miguel Angel Porrúa.

Bhabha, H. (2007). O local da cultura (4a ed.). Belo Horizonte: UFMG.

Bittar, M., Rodríguez, M. V., \& Almeida, C. E. M. (2006) Educação superior em Mato Grosso do Sul: 1991-2004. In D. Ristoff, \& J. Giolo (Ed.), Educação superior brasileira 1991-2004: Mato Grosso do Sul (p.402). Brasília: INEP.

Bourdieu, P. (1997). A miséria humana (2a ed.). Petrópolis: Vozes.

Brand, A. J., \& Calderoni, V. A. M. de O. (2012). Povos indígenas e formação acadêmica: ambivalências e desafios. Currículo sem Fronteiras, 12(1), 85-97. Recuperado em 12 de junho de 2015, de http://www.curriculosemfronteiras.org/vol12iss1articles/brandcalderoni.pdf

Brostolin, M. R., \& Cruz, S. F. (2010). Educação e sustentabilidade: o porvir dos povos indígenas no ensino superior em Mato Grosso do Sul. Interações, 11(1), 33-42. doi: 10.1590/S1518-70122010000100004.

Cordeiro, M. J. de J. A. (2008). Negros e indigenas cotistas da Universidade Estadual do Mato Grosso do Sul: desempenho acadêmico do ingresso à conclusão de curso. Tese de Doutorado em Educação, Pontifícia Universidade Católica, São Paulo.

Cordeiro, M. J. de J. A., \& Zarpelon, S. (2011). Indígenas cotistas da UEMS: acesso, permanência e evasão dos primeiros ingressantes em 2004. Educação e Fronteiras on-line, $1(1), 65-79$. 
Couto, R. (2009, setembro 13). Evasão indígena. Correio Brąiliense, p. 15.

Dayrell, J. (1996). A escola como espaço sociocultural. In J. Dayrell (Org.), Múltiplos olhares sobre educação e cultura (pp.136-161). Belo Horizonte: UFMG.

Elmore, R. F. (1996). Diseño retrospectivo: la investigación de la implementación y las decisiones políticas. In L. F. Aguilar Villanueva, Antologías de la política pública (pp. 251280). México: Miguel Angel Porrúa.

Giroux, H. (1997). Os professores como intelectuais: rumo a uma pedagogia crítica da aprendizagem. Porto Alegre: Artes Médicas.

Gusmão, N. M. de. (2003). Os desafios da diversidade na escola. In N. M. de Gusmão (Org.), Diversidade, cultura e educaşão: olhares cruzados (pp. 83-115). São Paulo: Biruta.

Lázaro, A. (2013). Prefácio: a questão indígena. In A. H. Aguilera Urquiza, \& A. C. Nascimento (2013), Rede de saberes: políticas de ação afirmativa no ensino superior para indígenas no Mato Grosso do Sul (pp. 9-23). Rio de Janeiro: FLACSO, GEA; UERJ, LPP.

Lima, A. C. de S. (2007). Ensino superior para indígenas: sobre cotas e algo mais. Seminário Formação Jurídica e Povos Indígenas: desafios para a educação superior. Belém: Laced.

Luciano, G. de S. (2006). O indio brasileiro: o que você precisa saber sobre os povos indigenas no Brasil de hoje. Brasília: Ministério da Educação.

Lynch, K., Crean, M., \& Moran, M. (2013). Igualdade e justiça social. In M. W. Apple, S. J. Ball, \& L. A. Gandin (Orgs.), Sociologia da educação: análise internacional (pp. 324-357, C. Monteiro, trad.). Porto Alegre: Penso.

Moehlecke, S. (2002). Ação Afirmativa: história e debates no Brasil. Cadernos de Pesquisa, 117, 197-217. Recuperado em 08 de novembro de 2015, http://www.scielo.br/pdf/cp/n117/15559.pdf

Molina, R. K., Lopes, R. A., \& Achilles, H. S. (2011). Impactos das políticas educacionais nas dinâmicas da organização escolar: reflexões na perspectiva do professorado de uma rede municipal. Ensaio: Avaliação e Políticas Públicas em Educação, 19(73), 921-940. doi: 10.1590/S0104-40362011000500010. 
Paz, A. A. M. Á. (2013). Indianizar para descolonizar a universidade: itinerâncias, políticas, éticas e epistemológicas com os estudantes indígenas da universidade de Brasilia. Tese de Doutorado, Faculdade de Educação, Universidade de Brasília.

Programa Rede de Saberes (2009). Relatórios do Levantamento dos Acadêmicos Indígenas nas IES de MS. Campo Grande: UCDB.

Rohrbach-Viadas, C. (1998). Introducción a la teoría de los cuidados culturales enfermeros de la diversidad y de la universalidad de Madeleine Leininger. Cultura de los Cuidados, 41, $41-45$.

Santos, B. de S. (2009). Para um novo senso comum: a ciência, o direito e a política na transição paradigmática (7a ed., Vol. 1). São Paulo: Cortez.

Santos, B. de S. (2010). A universidade no século XXI: para uma reforma democrática e emancipatória da universidade (3a ed.). São Paulo: Cortez.

SESAI - Secretaria Especial de Atenção à Saúde Indígena (2012). Dados epidemiológicos: Campo Grande: Distrito Sanitário Especial Indígena de Mato Grosso do Sul. Campo Grande: SESAI.

Silva, G. J. da, \& Souza, J. L. de (2008). Educar para a diversidade étnico-racial e cultural: desafios da educação inclusiva no Brasil. Inter-Ação, 33(1), 169-192.

Silva, T. T., Hall, S., \& Woodward, K. (2011). Identidade e diferença: a perspectiva dos estudos culturais (10a ed.). Rio de Janeiro: Vozes.

UEMS - Universidade Estadual de Mato Grosso do Sul. (2013). Divisão de Planejamento e Avaliação Institucional. Pró-Reitoria de Administração e Planejamento. Relatório anual de atividades físico-financeiras. Dourados: UEMS. Disponível em http://www.uems.br

UEMS - Universidade Estadual de Mato Grosso do Sul. (2014). Plano de Desenvolvimento Institucional PDI 2014-2018. Dourados: UEMS.

Urquiza, A. H. A., Nascimento, A. C., \& Espíndola, M. A. J. (2011). Jovens indígenas e o ensino superior em Mato Grosso do Sul: desafios e perspectivas na busca por autonomia e respeito à diversidade. Tellus, 11(20), 79-97. 
Van Meter, D. S., \& Van Horn, C. E. V. (1996). La implementación de las políticas. In L. F. Aguilar Villanueva, Antologías de la política pública (pp. 15-84). México: Miguel Angel Porrúa.

Veiga, J., \& D’Angelis, W. da R. (2010). Educação egocentrada X educação sociocentrada. Educere et Educare, 5(9), 63-71.

Woodward, K. (2009). Identidade e diferença: uma introdução teórica e conceitual. In T. T. Silva (Org.), Identidade e diferença: a perspectiva dos estudos culturais (6a ed., pp. 7-72). Petrópolis: Vozes.

Submetido à avaliação em 4 de setembro de 2016, revisado em 26 de setembro de 2017, aceito para publicação em 9 de outubro de 2017. 